\title{
Fragile X Tremor/Ataxia Syndrome
}

National Cancer Institute

\section{Source}

National Cancer Institute. Fragile X Tremor/Ataxia Syndrome. NCI Thesaurus. Code C126566.

An X-linked dominant inherited syndrome caused by mutations in the FMR1 gene. It is a late onset disorder, usually occurring after age 50 . It affects males more frequently than females. It is characterized by abnormalities in the cerebellum and white matter. It manifests with intention tremor, ataxia, and cognitive disabilities. The symptoms worsen with age. 